07,01

\title{
Структурно-временны́е особенности динамического деформирования наноструктурированных и наноразмерных металлов
}

\author{
(C) Н.С. Селютина ${ }^{1,2}$, И.Н. Бородин ${ }^{3}$, Ю.В. Петров ${ }^{1,2}$ \\ ${ }^{1}$ Санкт-Петербургский государственный университет, \\ Санкт-Петербург, Россия \\ ${ }^{2}$ Институт проблем машиноведения РАН, \\ Санкт-Петербург, Россия \\ ${ }^{3}$ Mechanics and Physics of Solids Research Group, School of MACE, the University of Manchester, Manchester, \\ M13 9PL, UK \\ E-mail: nina.selutina@gmail.com
}

(Поступила в Редакцию 6 февраля 2018 г.)

Дается развитие структурно-временно́го интегрального критерия текучести для описания динамической деформации металлов. Показано, что величины характерных времен релаксации, рассматриваемые как постоянные материала, можно применять для описания динамических эффектов при деформации наноматериалов в широком диапазоне скоростей внешних воздействий. Обсуждаются три различных способа определения характерного времени релаксации наноматериалов. На основе интегрального критерия текучести дается интерпретация поведения предельных напряжений в широком диапазоне длительностей нагружения с одной и с двумя точками смены преобладающего механизма скоростной чувствительности.

Исследование выполнено за счет гранта Российского научного фонда (проект 17-11-01053).

DOI: 10.21883/FTT.2018.09.46395.032

\section{1. Введение}

Исследования механических свойств экспериментально получаемых нанокристаллических (наноструктурированных) металлов [1-3] позволили сформулировать новые задачи о взаимосвязи наблюдаемых динамических эффектов пластического деформирования со структурой металла. Динамические эффекты в крупнозернистых металлах, микро- и наноразмерных нитевидных кристаллах [4], объемных наноматериалах $[5,6]$ наблюдаются при различных скоростях деформации.

Несмотря на увеличение данных по молекулярнодинамическому моделированию $[7,8]$ и развитию теоретических подходов на основе различных механизмов пластической релаксации до сих пор не сформулировано теории, описывающей различную реакцию материалов на внешнее воздействие на одних и тех же скоростях деформации. В частности, условие предельного критического напряжения

$$
\Sigma(t) \leq \sigma_{y}
$$

можно применять для поликристаллических образцов при не слишком высоких скоростях нагружения до $10^{-3} \mathrm{~s}^{-1}$, но недопустимо для наноразмерных нитевидных кристаллов [9] при тех же скоростях деформации; здесь $\Sigma(t)$ - действующее напряжение, $\sigma_{y}$ - предел текучести материала. В частности, испытания показывают, что при динамическом воздействии критическое напряжение уже не является константой материала, но проявляет сложную функциональную зависимость от временны́х характеристик процесса нагружения. Попытки свести данное явление к скоростным зависимостям предела текучести оказываются не слишком успешными, поскольку соответствующие функции не являются устойчивыми в силу их зависимости не только от скорости деформации, но и от многих других временны́х характеристик процесса воздействия. Таким образом, каждый материал имеет свою область скоростных нагрузок, где, в отличие от квазистатического деформирования, важно учитывать, что пластическая релаксация напряжений в материале происходит не мгновенно, а за некоторое конечное время.

Анализ экспериментов указывает на наличие эффекта задержки начала процесса текучести материала и подтверждает доминирующую роль инкубационной стадии на высоких скоростях деформации. Частным случаем является эффект ,дислокационного голодания“ материала $[1,4,10]$, когда плотности дислокаций не хватает для пластического течения с заданной внешними силами скоростью деформации. Особенно ярко он проявляется при деформации микро- и наноматериалов, в которых стоки дислокаций на границы зерен имеют важную роль и при этом средний пробег дислокаций уменьшается на порядки. В работах $[11,12]$ было отмечено, что переход от квазистатического к динамическому режиму деформации металлов осуществляется тогда, когда процесс пластичности начинает определяться не „динамикой“ существующих дефектов, а их кинетикой - т. е. скоростью увеличения их объемной доли. В работе [13] это явление задержки отклика материала на воздействие и сопут- 


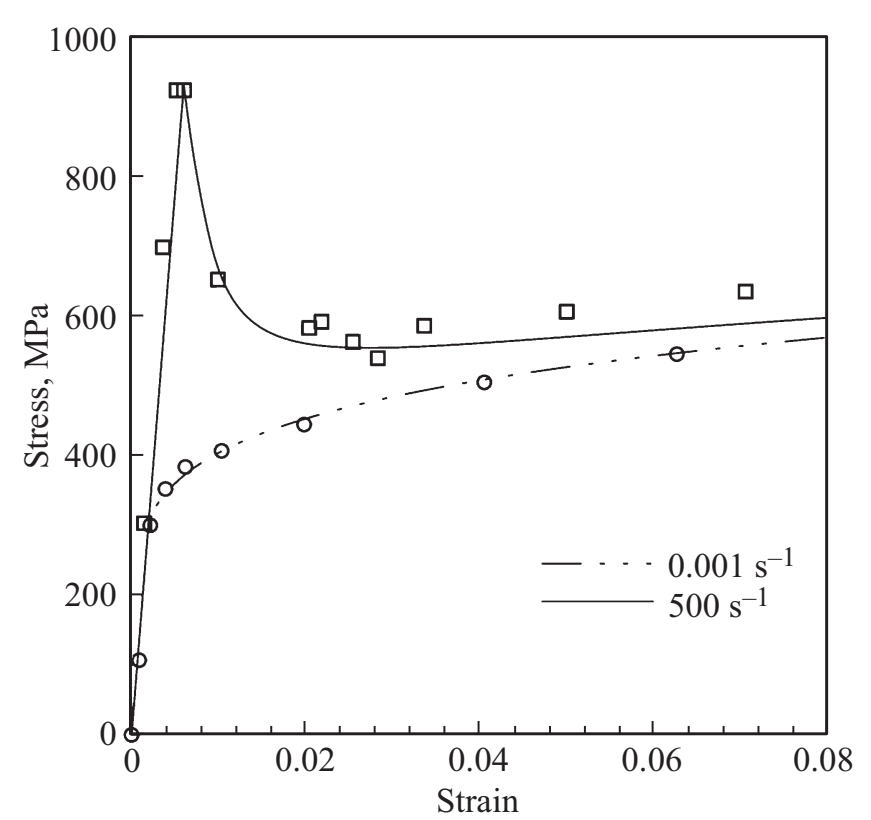

Рис. 1. Деформационные зависимости для стали (DP 600) [17] по релаксационной модели пластичности $[16](G=78 \mathrm{GPa}$; $\left.\sigma_{y}=310 \mathrm{MPa} ; \alpha=1\right)$.

ствующие ему механические эффекты были рассмотрены с позиций дислокационной динамики в широком диапазоне размеров диаметров зерен. Таким образом, необходимо вводить некоторую временну́ю характеристику материала, отражающую инкубационную стадию развития дефектной структуры, или его „инерционные“ свойства при пластической деформации.

В наших предыдущих работах $[14,15]$ была предложена релаксационная модель пластичности на основе инкубационного времени пластического деформирования или характерного времени релаксации, являющегося постоянной величиной для всего диапазона скоростей деформации и не зависящего от типа механизма пластической деформации. Эта модель объясняла и прогнозировала динамические эффекты пластичности, такие, например, как „зуб текучести“. В частности, было показано в [16], что качественный вид деформационной кривой существенно зависит от скоростного режима деформирования и появление „зуба текучести“ для стали DP600 [17] (на скорости деформации $500 \mathrm{~s}^{-1}$ ) определяется конкурентным отношением временны́х интервалов процесса локального нагружения и характерного времени релаксации материала (рис. 1). При помощи интегрального критерия текучести была получена зависимость предела текучести от скорости деформации при постоянной скорости деформации. Эта зависимость является линейной относительно скорости деформации до критической $\dot{\varepsilon}_{c r}=\sigma_{y} / G \tau$ при низких скоростях деформации $(G-$ модуль сдвига, $\tau$ - характерное время релаксации), что соответствует модели очень вязкой жидкости Максвелла $[18,19]$, и нелинейной при высоких скоростях деформации. Отметим необходимость проведения дополни- тельных экспериментов для установления структурной зависимости характерного времени релаксации. Полученные оценки характерных времен релаксации $[14,15]$ для образцов с различной структурой для квазистатических скоростей деформации при действии дислокационного скольжения и зернограничного проскальзывания совпадают в момент достижения материалом предела текучести. При этом абсолютные временны́е интервалы процесса текучести $[14,19]$, отвечающие определенному механизму пластичности (дислокационное скольжение, ползучесть, механическое двойникование), существенно зависят от самого процесса деформирования [20] и обратно пропорциональны скорости деформации.

В данной работе предлагаются методики определения характерных времен релаксации в случае деформации наноструктурированных материалов на основе значений релаксационных времен доминирующего механизма пластичности в конкретных диапазонах скоростей деформации. На основе сравнения поведения пределов текучести двух материалов, вычисленных при помощи интегрального критерия, показана принципиальная роль и необходимость введения и определения характерных времен релаксации.

\section{2. Динамическая теория текучести}

2.1. Общий вид интегрального критерия текучести. В качестве феноменологического подхода высокоскоростного деформирования, объясняющего широкий спектр временны́х и скоростных эффектов, эффективно работает интегральный подход, основанный на концепции „затухающей памяти“ и широко применяемый в механике полимеров [21]. Развитие феноменологических подходов для описания зависимости предела текучести металлов от скорости внешнего воздействия привело к формулировке импульсных критериев текучести [22]. Несмотря на соответствие с результатами динамических экспериментов, новые критерии не могли давать адекватные оценки предельных характеристик напряжения одновременно при динамических и квазистатических условиях нагружения. Применение введенной Работновым [23] функции затухания памяти $K(t)$ в качестве ядра интегрального оператора позволяет существенно улучшить получаемые оценки и предложить интегральный критерий в наиболее общем виде. Так, рассматривая условие

$$
I(t)=\int_{0}^{t} \Sigma(s) K(t-s) d s \leq \sigma_{y}
$$

и выбирая в качестве ядра $K(t)=\delta(t)$, где $\delta(t)-$ функция Дирака, получаем из (2) известную форму „статического“ предела текучести, определяемого только величиной порогового напряжения (1). Если же мы возьмем $K(t)$ в экспоненциальном виде $K(t)=\tau^{-1} \exp (-t / \tau)$, предполагая модель Фойгта с телом Сен-Венана [19] и 
величиной характерного времени релаксации $\tau=\mu / 2 G$ (здесь $\mu-$ параметр вязкости материала), то в случае замены экспоненциального затухания на кусочногладкую функцию, мы получим

$$
K(t)= \begin{cases}\tau^{-1}, & 0 \leq t \leq \tau, \\ 0, & t>\tau .\end{cases}
$$

Тогда интегральный критерий (2) принимает вид $[14,15,24-29]$

$$
\frac{1}{\tau} \int_{t-\tau}^{t} \Sigma(s) d s \leq \sigma_{y} .
$$

Условие (4) означает, что текущие значения напряжений $\Sigma(t)$ могут значительно превышать критические напряжения $\sigma_{y}$ в течение коротких промежутков времени $t \leq \tau$, что почти не отражается на их среднем значении [14]. Отметим, что знак равенства в (4) позволяет при известной функции локального нагружения $\Sigma(t)$ определить момент времени начала пластического течения $t=t_{y}$ и соответствующее значение напряжения текучести $\left(\Sigma_{d}=\Sigma\left(t_{y}\right)\right)$. Аналогичная физическая интерпретация динамического процесса начала текучести, проведенная Петровым и Груздковым [25-29], позволила ввести независимый временно́й параметр $\tau$, характеризующий динамические особенности процесса. Предполагается, что характерное время релаксации $\tau$, как свойство материала, зависит от начальной микроструктуры материала до начала нагружения, но не от скорости деформирования, и является интегральной характеристикой механизма пластической деформации в материале. Подробная физическая интерпретация $\tau$ представлена в [14]. Для расчета зависимости предела текучести от скорости деформации для крупнозернистых металлов в широком диапазоне скоростей деформации [25-29] интегральный критерий текучести применяется в общей форме

$$
\frac{1}{\tau} \int_{t-\tau}^{t}\left(\frac{\Sigma(s)}{\sigma_{y}}\right)^{\alpha} d s \leq 1,
$$

где $\alpha-$ параметр чувствительности материала к уровню интенсивности (амплитуде) локальных напряжений $\Sigma(t)$. Одной из главных особенностей критерия (5) является наличие независимых параметров, один из которых характеризует скоростную чувствительность материала $(\tau)$, а другой - амплитудную $(\alpha)$. Для меди и никеля было получено [14], что $\alpha=1$ дает хорошее соответствие с экспериментальными данными, т.е. в этом случае можно применять критерий (4).

Выполняя интегрирование в (4) при постоянной скорости деформации $\dot{\varepsilon}=$ const, когда $\Sigma(t)=2 G \dot{\varepsilon} t H(t)$, получаем зависимость предельного значения напряжения в момент текучести $\Sigma_{d}=\Sigma\left(t_{y}\right)$ от времени начала текучести $t_{y}$, отсчитываемого от момента приложения воздействия и определяемого из условия выполнения равенства в (4)

$$
\Sigma_{d}\left(t_{y}\right)= \begin{cases}2 \sigma_{y}\left(\tau / t_{y}\right), & t_{y} \leq \tau, \\ \frac{2 \sigma_{y}}{2-\left(\tau / t_{y}\right)}, & t_{y}>\tau,\end{cases}
$$

а также зависимость от скорости деформации в виде

$$
\Sigma_{d}(\dot{\varepsilon})= \begin{cases}\sqrt{4 G \dot{\varepsilon} \tau \sigma_{y}}, & t_{y} \leq \tau, \\ \sigma_{y}+G \dot{\varepsilon} \tau, & t_{y}>\tau .\end{cases}
$$

В силу принятого нами условия постоянства скорости деформирования $\dot{\varepsilon}=$ const, мы можем связать $t_{y}$ со значением $\dot{\varepsilon}$ и $\dot{\varepsilon}_{c r}$ [14]. Полученное выражение показывает, что интегральный критерий текучести (5) позволяет в рамках одного подхода описывать поведение предела текучести материала при медленном $\left(t_{y}>\tau\right.$ или $\left.\dot{\varepsilon}<\dot{\varepsilon}_{c r}\right)$ и быстром деформировании $\left(t_{y} \leq \tau\right.$ или $\left.\dot{\varepsilon} \geq \dot{\varepsilon}_{c r}\right)$.

Получаемая здесь условная критическая скорость перехода $\dot{\varepsilon}_{c r}=\sigma_{y} / G \tau$ от малых скоростей к высоким скоростям деформации полностью определяется параметрами материала и никак не зависит от внешних условий его нагружения. Скорости деформации до значений $10 \mathrm{~s}^{-1}$ традиционно считают „низкими“ (или „квазистатическими“), после - „высокими“. Анализируя зависимость (7), можно дать более общие определения. В случае медленного деформирования (или „низких“ скоростей деформации), напряжения в материале существенно не превышают его статический предел текучести. Напротив, в случае быстрого деформирования (или „высоких“ скоростей деформации), напряжения в материале принимают значения, значительно превышающие значение статического предела. Другими словами, определение условной границы между „низкими“ и „Высокими“ скоростями деформации как $10 \mathrm{~s}^{-1}$ связано только с технологическими особенностями нагружения, в действительности же эта граница для каждого материала зависит от его реакции на быструю нагрузку, определяемой в значительной мере характерным временем релаксации. Например, для нитевидных кристаллов меди [9] справедливо условие $\dot{\varepsilon}_{c r} \leq 10^{-3} \mathrm{~s}^{-1}$. Оценки характерного времени релаксации для этих экспериментов составили $11 \mathrm{~s} \mathrm{[15],} \mathrm{что} \mathrm{существенно} \mathrm{больше} \mathrm{полученных}$ нами типичных значений характерных времен для поликристаллов алюминия, меди и мягких сталей, которые варьировались от микро- до наносекунд.

Таким образом, поведение предела текучести при быстром деформировании может быть спрогнозировано с помощью характерного времени релаксации вне зависимости от предполагаемых значений предельной скорости деформации. Используя метод наименьших квадратов и экспериментальную зависимость предела текучести от скорости деформации применительно к (6) или (7), мы можем оценить $\tau$ из измеренных скоростных зависимостей. 
2.2. Определение характерных времен релаксации на основе доминирующего механизма пластичности. Применение интегрального критерия текучести ставит вопрос об экспериментальных методах измерения характерного времени релаксации как параметра материала, а также о диапазоне его изменения для разных металлов. С одной стороны, характерное время релаксации не зависит от механизма пластичности. С другой - недавно проведенные исследования [14] показали, что в определенном диапазоне скоростей деформации эти времена имеют тот же порядок, что и времена релаксации того доминирующего механизма пластичности, который присутствует в металле.

Приведем примеры определения времен релаксации в зависимости от механизма пластичности, которые давали соответствие с оцененными характерными временами релаксации по интегральному критерию текучести. Хорошее соответствие с экспериментами по динамической деформации чистых металлов, в том числе нанокристаллического никеля [5], показывает соотношение для величины времени релаксации для механизма дислокационной пластичности [14] как функции от плотности дислокаций и постоянных его кристаллической решетки

$$
\tau_{D}=\frac{8 \chi B_{f}}{3 \rho_{D} G b^{2}},
$$

где $B_{f}-$ величина фононного трения дислокаций, $b$ - вектор Бюргерса, $G$ - модуль сдвига, $\chi-$ „квазирелятивистский“ коэффициент [30] (при низких скоростях деформации $\chi=1$, при высоких скоростях деформации $\chi \neq 1), \rho_{D}-$ скалярная плотность дислокаций. С одной стороны, зависимость (8) дает хорошие результаты при описании данных молекулярнодинамического моделирования деформации нитевидных наноразмерных кристаллов металлов. В материалах типа нитевидных кристаллов с большими значениями характерных времен, полученных по интегральному критерию текучести (7), эти времена релаксации оказываются сопоставимы со временем начала пластического течения и динамические эффекты ярко проявляются в виде „зубов текучести“ $[9,16,17]$ или задержки начала текучести [31] при обычных медленных „квазистатических“ деформациях. Помимо дислокационного механизма пластичности в случае нанокристаллических металлов необходимо рассматривать механизм зернограничного проскальзывания. Этот механизм дает доминирующий вклад в пластическую деформацию материала при размере зерна менее $20 \mathrm{~nm}$. При молекулярно-динамических исследованиях [8] была получена зависимость скорости деформации наноматериалов от размеров зерна при экстремально высоких скоростях более $10^{7} \mathrm{~s}^{-1}$, на основании чего в работе [32] была предложена зависимость для величины времени релаксации в виде

$$
\tau_{g b}^{M D}=\frac{k_{b} T d}{6 G b v V_{s}} \exp \left\{\frac{U_{b}}{k_{b} T}\right\},
$$

которая хорошо согласуется с различными молекулярнодинамическими расчетами [32]. Характерное время ре-

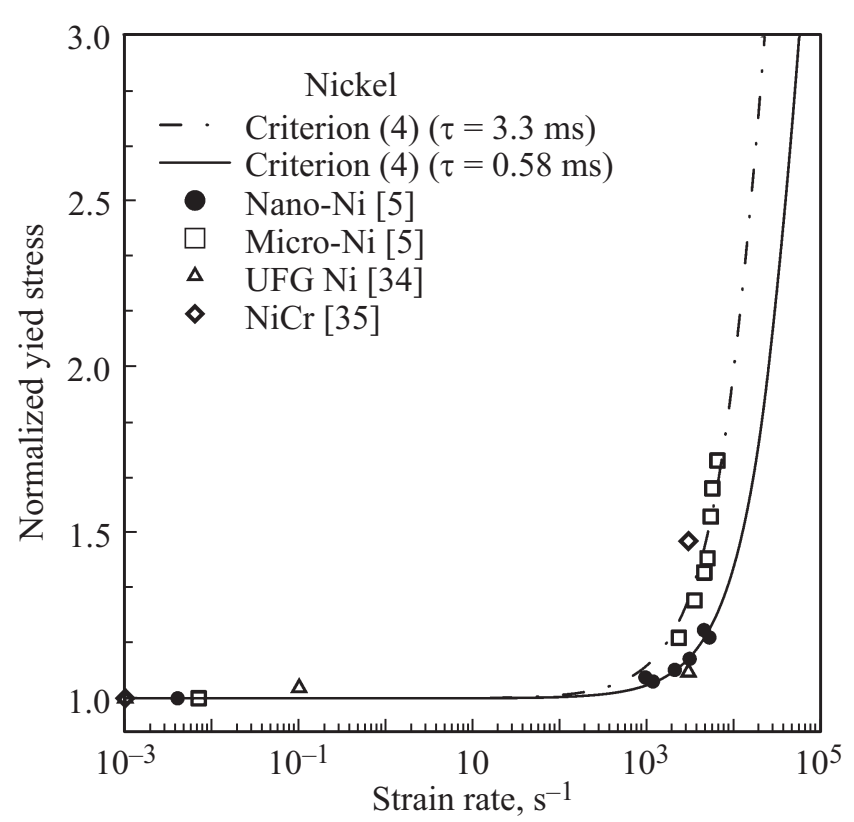

Рис. 2. Скоростная зависимость динамического предела текучести для микро- и нанокристаллического никеля [5], а также ультрамелкозернистого никеля [34] и $\mathrm{NiCr}$ стали [35].

лаксации при этом для меди и никеля можно оценить как $\sim 10^{-11} \mathrm{~s}$. При применении этой зависимости к динамическим экспериментам со значительно более низкими скоростями деформации порядка $10^{3}-10^{4} \mathrm{~s}^{-1}$ она оказалась неточной и в работе [33] была предложена зависимость, на основе классической модели зернограничной ползучести Кобла

$$
\tau_{g b}^{\text {Goble }}=\frac{k_{b} T d^{3}}{A_{c} G b^{3} D_{g b} \delta} .
$$

Зависимость (10) дает характерные времена релаксации порядка микросекунд, хорошо согласующиеся с экспериментами для умеренно высоких скоростей деформации [33].

Рассмотрим три метода определения характерных времен релаксации по критической точке перехода $\dot{\varepsilon}_{c r}$, эффекту „зуба текучести“, эффекту „задержки“ начала текучести.

На основе модели Максвелла для очень вязкой жидкости, $\Sigma_{d} \sim \sigma_{y}+G \dot{\varepsilon}_{p l} \tau$, мы можем определить время релаксации. Полученные данные для меди, алюминия и мягких сталей дают значения времен релаксации в диапазоне от десятков пикасекунд до нескольких микросекунд со средним значением около микросекунды [14], совпадающие с оценками по интегральному критерию текучести. На рис. 2 показана скоростная зависимость динамического предела текучести (нормированная на величину статического предела текучести) для микро- и нанокристаллического [5], а также ультрамелкозернистого никеля [34] и $\mathrm{NiCr}$ стали [35]. Найденные по критической точке перехода $\dot{\varepsilon}_{c r}$ характерные времена составили $\sim 0.6 \mu \mathrm{s}$ и $\sim 3 \mu \mathrm{s}$ соответственно, т. е. характерное время 
для нанокристаллического никеля приблизительно в 5 раз больше, чем для микрокристаллического никеля. На фоне наблюдаемых отличий характерных времен на несколько порядков для металлов с различной микроструктурой эти различия можно считать незначительными. Все эти данные хорошо согласуются с характерными временами релаксации, найденными аналогичным способом на основе интегрального критерия текучести [14].

Явление зуба текучести на деформационных кривых металлов, в особенности сталей, известно достаточно давно [36,37], но только в последние десятилетия развитие экспериментальной техники сделало возможным детальные исследования начальных стадий пластической деформации при постоянной скорости нагружения [4,31]. При этом было предложно два возможных объяснения этому явлению: блокировка дислокационных линий примесями, в результате чего требуется большее напряжение для начального выхода дислокации из окружающей ее примесной „атмосферы“, после чего она может двигаться в обычном режиме при напряжении, соответствующем статическому пределу текучести материала; другая точка зрения [37] состоит в том, что если в материале по каким-либо причинам осталось мало подвижных дислокаций, которые хотя бы в принципе могут перемещаться, то ввиду ограниченности их скорости (согласно соотношению Орована $\left.\dot{\varepsilon}_{p l}=\rho_{D} b V_{D}\right)$ возникает явление „дислокационного голодания““. Скорость дислокаций при квазистатической деформации обычно колеблется от единиц до сотен метров в секунду, соответственно, если подвижных дислокаций в материале достаточно мало, то их может не хватить для того, чтобы при данном уровне внешних напряжений обеспечить скорость пластической деформации, сравнимую со скоростью деформации всего материала (определяемую параметрами внешнего воздействия). Во втором случае последующее падение напряжений до величины статического предела текучести определяется кинетическими процессами увеличения числа подвижных дислокаций. Возможна также реализация промежуточного варианта, когда оба этих случая имеют место с разной степенью значимости каждого из них. Принципиальным является случай, когда два механизма возникновения зуба текучести на деформационной кривой отражают два различных взгляда на пластическую деформацию: статический и динамический. Обычная классификация максимально достигаемого и минимального (после зуба текучести) напряжений течения, как „верхнего“ и „нижнего“ пределов текучести, отражает квазистатический взгляд, согласно которому оба этих „предела текучести“ являются постоянными характеристиками материала и пластическое течение начинается мгновенно при превышении значений этих пороговых величин локальными напряжениями. Второй вариант предполагает динамический механизм, в котором величина „динамического“ предела текучести уже не является характеристикой материала, но зависит от скорости деформации и других факторов. В рассматриваемом нами подходе эта зависимость объясняется наличием релаксационного процесса, ключевым параметром

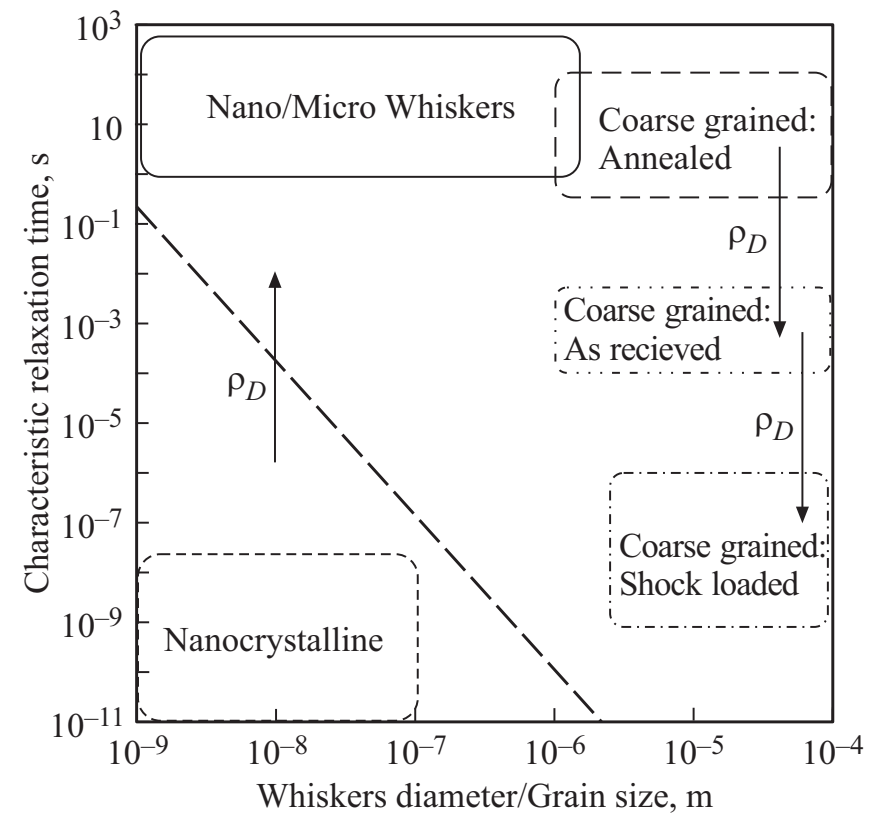

Рис. 3. Значения характерных времен релаксации для различных размеров материала и его микроструктуры.

которого является характерное время релаксации [15]. Механизм резкого увеличения предела текучести, становящегося по сути „динамическим“, остается абсолютно аналогичным предыдущему случаю и только очень большие значения характерных времен релаксации могут его обеспечить при низких скоростях деформации. При увеличении характерного времени релаксации до $1 \mathrm{~s}$ и выше критической скорости деформации, при которой совершается переход к динамической ветви кривой, стремится к величинам менее $10^{-2} \mathrm{~s}^{-1}$, т.е. типичным для квазистатических условий деформации.

Величина характерного времени при этом может быть найдена по величине зуба текучести - максимальному напряжению, достигаемому в металле в процессе деформации. Наши оценки для микроразмерных нитевидных кристаллов (диаметром порядка микрометров) [15] дали значения характерных времен порядка нескольких секунд. Для нанометровых нитевидных кристаллов времена составляют уже сотни секунд и стремятся к $1000 \mathrm{~s}$. На рис. 3 показана диаграмма характерных времен релаксации в зависимости от размера образца или размера элементов его микроструктуры. Нанокристаллические металлы располагаются в левом нижнем углу рис. 3 . Видно, что структурирование образца относительно мало изменяет его динамические характеристики, отражаемые величиной характерного времени. Это подтверждают также последние динамические эксперименты с ультрамелкозернистыми металлами [6,38], где эффекты микроструктуры присутствуют, но оказываются слабо выраженными. При этом уменьшение размеров самого образца до микронных и субмикрометровых размеров существенно изменяет его характеристики. Схематически показано изменение скалярной плотности дислока- 


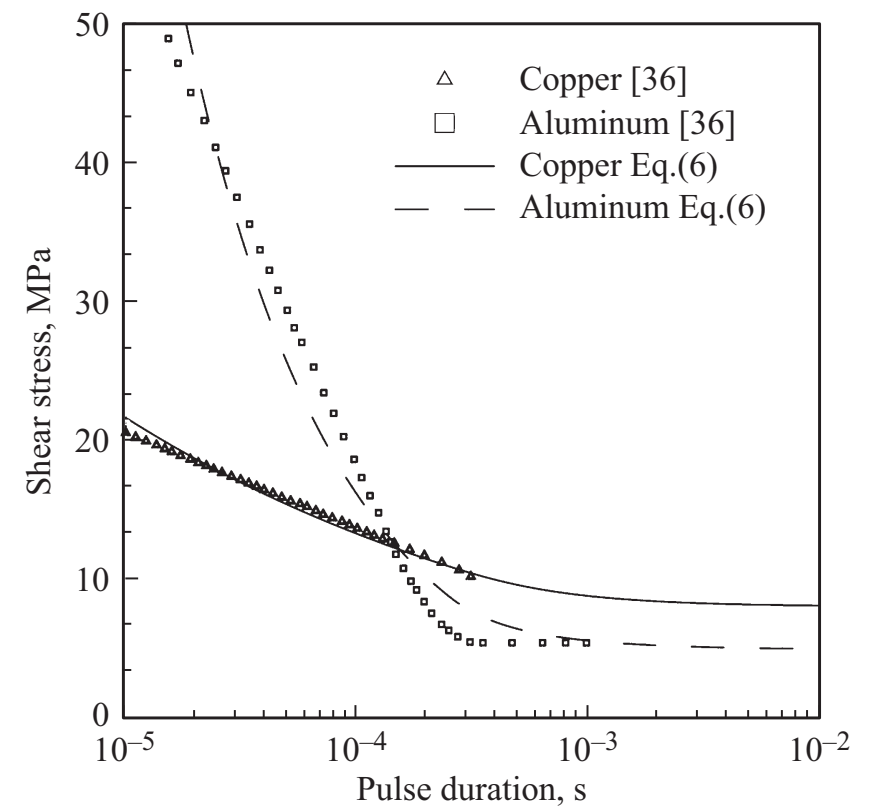

Рис. 4. Зависимость предела текучести от длительности импульса для монокристаллов алюминия $(\tau=0.24 \mathrm{~ms}$, $\left.\sigma_{y}=4.9 \mathrm{MPa}\right)$ и меди $\left(\tau=0.19 \mathrm{~ms}, \sigma_{y}=8 \mathrm{MPa}\right)$ [36] на основе интегрального критерия текучести.

ций (стрелки соответствуют направлению увеличения плотности), которая повышается в правой части рис. 3, понижая при этом величину характерного времени при чисто дислокационной пластичности и повышается при переходе от нанокристаллических металлов (механизм зернограничного проскальзывания) к наноразмерным (дислокационная пластичность и двойникование).

Задержка необходима для того, чтобы деформация с единичных актов дислокационной пластичности распространилась на макроуровень и могла быть зафиксирована экспериментально (см. рис. 4). Это может быть осуществлено из прямых экспериментов по „задержке“ пластичности при малых длительностях нагружающего импульса. Время приложения нагрузки, начиная с которой при ее дальнейшем уменьшении необходимо непрерывно увеличивать амплитуду напряжения, чтобы зафиксировать остаточную пластическую деформацию в материале, может считаться величиной его характерного времени релаксации. В частности, эта величина составила доли миллисекунд в классических экспериментах на меди и алюминии [36].

2.3. Интерпретация инверсии пределов текучести в условия динамики. Определяя характерные времена релаксации, мы можем анализировать динамические свойства предела текучести и выбирать материал с наиболее подходящими свойствами для требуемых условий нагрузки. Рассмотрим эффект конкуренции (инверсии пределов текучески) между двумя материалами [36]. На рис. 4 показаны зависимости предельного напряжения от длительности нагружения для монокристаллов алюминия и меди [36], построенные на основе интегрального критерия текучести (6) для случая $\alpha=1$. Были получены оценки характерного времени релаксации по интегральному критерию текучести для алюминия $\tau=0.24 \mathrm{~ms}$ и меди $\tau=0.19 \mathrm{~ms}$. На малых длительностях нагружения значение предельного напряжения $t_{y}<0.5 \mathrm{~ms}$ значение предельного напряжения у алюминия $\left(\tau=0.24 \mathrm{~ms}, \sigma_{y}=4.9 \mathrm{MPa}\right)$ больше, чем у меди $\left(\tau=0.19 \mathrm{~ms}, \sigma_{y}=8 \mathrm{MPa}\right)$. Наоборот, для длительностей нагружения $t_{y}>0.5 \mathrm{~ms}$ большее предельное напряжение у меди. С точки зрения критерия (7), материал с наибольшим характерным временем релаксации обладает лучшей скоростной чувствительностью $(\tau=0.24 \mathrm{~ms})$ и соответственно большим предельным напряжением на малых длительностях нагружения $\left(t_{y}<\tau\right)$. Таким образом, возникает эффект конкуренции (инверсии прочности) между двумя материалами, характеризующийся сменой преобладающей скоростной чувствительности. Как показано на рис. 4, алюминий, у которого значение характерного времени релаксации больше, чем у меди, имеет меньшее значение статического предела текучести, но большее предельное напряжение при малых длительностях нагружения $\left(t_{y}<\tau\right)$. Это позволяет делать выбор в рассматриваемом диапазоне длительности нагружения в пользу материала либо с лучшей характеристикой скоростной чувствительности $\tau$ при коротких импульсах или с лучшей характеристикой статического предела текучески $\sigma_{y}$ при длительных импульсах.

Точка смены преобладающей скоростной чувствительности (рис. 4) соответствует промежутку времени, начиная с которого плотность дефектов, содержащихся в материале, становится достаточной для того, чтобы релаксация напряжений в материале произошла. Смена преобладающей скоростной чувствительности для алюминия при длительности порядка $0.5 \mathrm{~ms}$ соответствует величине его характерного времени релаксации. Плотность дислокаций можно оценить на основе теоретических зависимостей по (8) и времени на рис. 4, определяемого точкой перегиба графиков, для параметров алюминия $G=26 \mathrm{GPa}, B_{f}=10^{-5} \mathrm{~Pa} \cdot \mathrm{s}$, $b=0.289 \mathrm{~nm}[39]: \rho_{D} \sim 10^{7} \mathrm{~m}^{-2}$. Для параметров меди $G=47 \mathrm{GPa}, B_{f}=10^{-4} \mathrm{~Pa} \cdot \mathrm{s}, b=0.256 \mathrm{~nm}$ при той же плотности дислокаций получаем характерное время $\sim 0.1 \mathrm{~ms}$, что сопоставимо с характерным временем для алюминия (рис. 4). Порядок величин, определяемый точкой смены преобладающей скоростной чувствительности по экспериментальной зависимости, больше относительно теоретических значений, а плотности дислокаций соответственно меньше (как в [15]), чем аналогичные величины, типичные для крупнозернистых металлов, что может соответствовать случаю искусственно выращенных монокристаллов.

В данном случае характерные времена релаксации алюминия $(\tau=0.24 \mathrm{~ms})$ и меди $(\tau=0.19 \mathrm{~ms})$ одного порядка ms и наблюдается одна точка смены скоростных механизмов. Эта может быть связано с тем, что медь имеет как большую величину статического предела текучести, так и большую величину наклона „динамической“ 
части кривой. Можно показать из (5), что этот наклон пропорционален произведению характерного времени релаксации материала на его статический предел текучести $\tau \cdot \sigma_{y}$.

2.4. Динамические эффекты пластичности материалов с разными величинами характерных времен релаксации. В качестве примера, демонстрирующего влияние величины характерного времени релаксации на пластическое поведение материала, рассмотрим механическое поведение двух металлов со значениями характерных времен релаксации $1 \mathrm{~s}$ и $0.6 \mu \mathrm{s}$, отличающихся друг от друга на 6 порядков. Эти величины, как было показано в предыдущих разделах, соответствуют значениям характерных времен для наноразмерных нитевидных кристаллов (или, наоборот, почти бездефектных монокристаллических образцов металлов) и объемных поликристаллических, в том числе нанокристаллических, образцов металлов. На рис. 5 показаны такие кривые с параметрами, соответствующими экспериментальным работам [5,40]. Интересно отметить две точки смены преобладающей скоростной чувствительности (два пересечения кривых) и, соответственно, три области, в которых материалы ведут себя различным образом друг относительно друга. При больших временах процесса (длительностях импульса) мы имеем пластическое течение, определяемое обычной „квазистатической“ величиной предела текучести материала, которая для никеля оказывается несколько больше. Точка смены скоростной чувствительности, как и на рис. 4, показывает критическое время воздействия $t_{y}$, при котором начинают проявляться временные динамические эффекты и фактически оно соответствует (см. рис. 5) величине характерного времени релаксации. В данном случае для железа это время значительно выше, что приводит к резкому росту его динамического предела текучести, который превышает предел текучести никеля в широком диапазоне длительностей импульса $0.1 \mathrm{~s}-10 \mu \mathrm{s}$. В большой части этого диапазона до длительностей воздействия $1 \mu \mathrm{s}$ никель ведет себя еще „квазистатически“ и его предел текучести равен постоянной величине. Эта первая смена преобладающей скоростной чувствительности полностью определяется тем, что материал с меньшим значением предела текучести имеет большее характерное время релаксации - т. е. отношением $\tau / \sigma_{y}$. Во второй области динамический предел текучести железа становится больше соответствующей величины для никеля, т.е. никель при этих средних длительностях воздействия становится более пластичным, чем железо. Наконец, вторая смена преобладающей скоростной чувствительности в области длительности воздействия $10 \mathrm{~ns}$ связана с большим наклоном динамической кривой железа, который, как уже было сказано, определяется произведением $\tau \cdot \sigma_{y}$. В данном случае критическим фактором является очень большая величина характерного времени релаксации для железа. Для длительностей импульса менее наносекунды (что характерно для лазерных ультракоротких импульсных воздействий на металлы) железо вновь становится

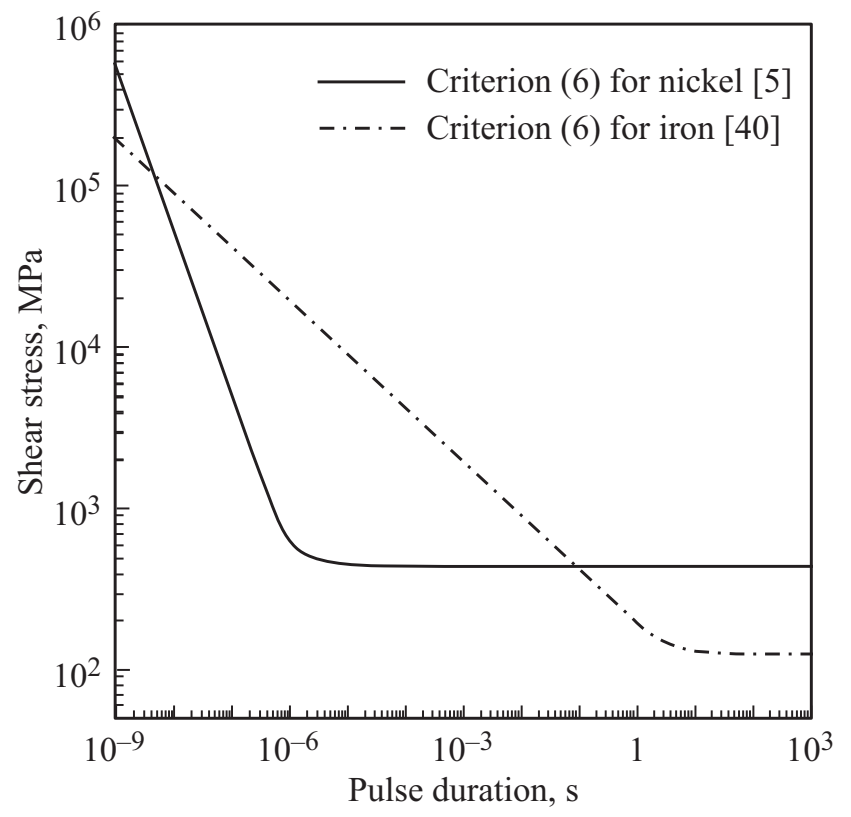

Рис. 5. Расчетная зависимость предела текучести нитевидных кристаллов железа и поликристаллического никеля от длительности импульса. Параметры моделей взяты из соответствующих экспериментальных работ $[5,40]$.

пластичнее никеля с меньшим значением динамического предела текучести. Таким образом, в зависимости от соотношения между статическим пределом текучести и характерным временем релаксации могут существовать области длительности воздействий (импульсов), в которых одни материалы становятся более или менее пластичные, чем другие. В случае если деформация сопровождается эффектами разрушения, это может соответствовать явлению вязкохрупкого перехода в динамике.

\section{3. Заключение}

На основе интегрального критерия текучести прогнозируется механическое поведение пределов текучести металлических материалов в зависимости от скорости деформации и длительности нагружения.

Показано, что величина характерного времени релаксации в случае малых образцов зависит от их размера и изменяется быстрее при уменьшении размеров образца до микронных и субмикрометровых размеров, чем при наноструктурировании макроскопического образца.

Обсуждается один из трех методов определения характерных времен релаксации по эффекту „задержки“ предела текучести, а также дается объяснение получаемым механическим эффектам для двух различных металлов, связанных со сменой преобладающей скоростной чувствительности.

Проведено сравнение поведения вычисленного предельного напряжения в широком диапазоне длительностей между монокристаллами алюминия и меди с 
разными характерными временами релаксации одного порядка. Материал с большим характерным временем релаксации может иметь больший предел текучести на более коротких импульсах, в то время как в случае длительных импульсов значение предельного напряжения текучести у него может быть меньше.

Возможное различие на шесть порядков характерных времен релаксации показало существование трех интервалов длительностей воздействия, где механическое поведение двух материалов может конкурировать. При переходе к диапазону длительностей импульса, определяемому двумя точками пересечения временных (скоростных) зависимостей двух материалов, один из материалов может стать более (или менее) пластичным, чем другой. Таким образом, наблюдаемый эффект конкуренции пределов текучести двух материалов в широком диапазоне длительностей импульсных воздействий может быть эффективно предсказан и объяснен на основе структурно-временно́й модели, базирующейся на понятии характерного времени релаксации.

\section{Список литературы}

[1] J.R. Greer, J.Th.M. de Hosson. Prog. Mater. Sci. 56, 654 (2011).

[2] A.S. Khan, B. Farrokh, L. Takas. J. Mater. Sci. 43, 3305 (2008).

[3] Mechanical Properties of Nanocrystalline Materials/ Eds J.C.M. Li/ Pan Stanford Publishing, Singapore (2011). 332 p.

[4] G. Dehm. Prog. Mater. Sci. 54, 664 (2009).

[5] S. Rajaraman, K.N. Jonnalagadda, P. Ghosh. In: Conference Proceedings of the Society for Experimental. Mech. Ser. 1 (2013). p. 157.

[6] С.В. Разоренов, Г.И. Канель, Г.В. Гаркушин, О.Н. Игнатова. ФTT 54, 742 (2012).

[7] J. Schiotz, T. Vegge, F.D. di Tolla, K.W. Jacobsen. Phys. Rev. B 60, 11971 (1999).

[8] H.V. Swygenhoven, A. Caro. Phys. Rev. B 58, 11246 (1998).

[9] S.S. Brenner. J. Appl. Phys. 27, 1484 (1956).

[10] Y. Cui, G. Po, N. Ghoniem. Acta Mater. 108, 128 (2016).

[11] R.W. Armstrong, F.J. Zerilli. J. Phys. D 43, 492002 (2010).

[12] P. Barai, G.J. Weng. Int. J. Plast. 25, 2410 (2009).

[13] E.N. Borodin, A.E. Mayer. Mod. Simul. Mater. Sci. Eng. 24, 025013 (2016)

[14] N. Selyutina, E.N. Borodin, Y. Petrov, A.E. Mayer. Int. J. Plast. 82, 97 (2016).

[15] Ю.В. Петров, И.Н. Бородин. ФТТ 57, 336 (2015).

[16] Y. Petrov, E. Borodin, E. Cadoni, N. Selyutina. EPJ Web Conf. 94, 04039 (2015).

[17] E. Cadoni, F. D’Aiuto, C. Albertini. DYMAT 1, 135 (2009). DOI: $10.1051 /$ dymat/2009018

[18] L.D. Landau, E.M. Lifshitz. Theory of Elasticity. In: Course of Theor. Physics 7. Pergamon, N. Y. (1986).

[19] M. Reiner. Rheology. Springer-Verlag, Berlin. (1958).

[20] P. Perzyna. Constitutive modelling of dissipative solids for localization and fracture. In: Localization and Fracture Phenomena in Inelastic Solids. Springer-Verlag. Wein GmbH, (1998).
[21] A.S. Wineman, K.R. Rajagopal, Mechanical Response of Polymers. An Introduction. Cambridge University Press (2000). 313 p.

[22] J.D. Campbell. Acta Metallurgica 1, 706 (1953).

[23] Ю.Н. Работнов. Элементы наследственной механики твердых тел. Наука, М. (1977). 383 с.

[24] И.Н. Бородин, А.Е. Майер, Ю.В. Петров, А.А. Груздков. ФTT 56, 2384 (2014).

[25] А.А. Груздков, Ю.В. Петров. Докл. РАН 364, 766 (1999).

[26] А.А. Груздков, Ю.В. Петров, В.И. Смирнов. ФТТ 44, 1987 (2002).

[27] Ю.В. Петров, Е.В. Ситникова. ЖТФ 75, 71 (2005).

[28] Ю.В. Петров, А.А. Груздков, Е.В. Ситникова. Докл. РАН 417, 493 (2007)

[29] A.A. Gruzdkov, E.V. Sitnikova, N.F. Morozov, Y.V. Petrov. Mathemat. and Mechan. Solids 14, 72 (2009).

[30] A.E. Dudorov, A.E. Mayer. Vestn. Chelyabinsk State Univ. Phys. 39, 39, 48 (2011).

[31] S.Y. Kuan, J.C. Huang, Y.H. Chen, C.H. Chang, C.H. Hsieh, J.H. Wang, Y.C. Nian, S.P. Ju, T.G. Nieh, S.H. Chen, Y.M. Hwang. Mater. Sci. Eng. A 646, 135 (2015).

[32] И.Н. Бородин, А.Е. Майер. ФТТ 54, 759 (2012).

[33] E.N. Borodin, N.S. Selyutina, Yu.V. Petrov, A.E. Mayer. Mater. Phys. Mechan. 26, 42 (2016).

[34] G.T. Gray III, T.C. Lowe, C.M. Cady, R.Z. Valiev, I.V. Aleksandrov. Nano-Structured Mater. 9, 447 (1997).

[35] P.R. Guduru, P.R. Singh, G. Ravichandran, A.J. Rosakis. J. Mech. Phys. Solids 46, 10, 1997 (1998).

[36] F.A. Mc Clintock, A.S. Argon. Mechanical Behaviour of Materials. Addison-Wesley, USA (1966).

[37] W.G. Johnston. J. Appl. Phys. 33, 2716 (1962).

[38] A.N. Petrova, I.G. Brodova, S.V. Razorenov. Phys. Met. Met. 118, 601 (2017).

[39] V.S. Krasnikov, A.E. Mayer, A.P. Yalovets. Int. J. Plast. 27, 1294 (2011).

[40] G.T. Hahn. Acta Met. Mater. 10, 727 (1962).

Редактор Т.Н. Василевская 